\title{
ALIH FUNGSI LAHAN PERTANIAN MENJADI KAWASAN PEMUKIMAN DI KECAMATAN POLEWALI KABUPATEN POLEWALI MANDAR
}

\author{
Rustan Ir*, Muhammad Syaeba
}

\begin{abstract}
ABSTRAK
Transfer of Agricultural Land Function into Settlement Area in Polewali Mandar District Polewali District. Increasing the number of residents indirectly affects the amount of housing demand. The construction of housing areas in Polewali Subdistrict, Polewali Mandar Regency has increased along with population growth. For these activities, developers often utilize and convert agricultural land. In this case the Regional Government through the RTRW Regulation No.2 of 2013 concerning the 2012-2032 Polewali Mandar District Spatial Plan has a role in regulating and controlling the use of agricultural land. This study uses a qualitative method with a descriptive approach. In this study the results showed that the conversion of agricultural land to the construction of residential areas was regulated in the establishment of spatial patterns for residential areas, while the percentage of agricultural land diverted to housing was 2,091 ha with uneven distribution in all Polewali Mandar Districts.
\end{abstract}

Keywords: Transfer function of land, agriculture, residential area

\section{PENDAHULUAN}

Indonesia merupakan negara agraris dimana pertanian merupakan basis utama perekonomian nasional. Sebagian besar masyarakat Indonesia masih menggantungkan hidupnya pada sektor pertanian. Sektor pertanian telah memberikan sumbangan besar dalam pembangunan nasional dan Indeks Pembangunan Manuasia. Lahan merupakan sumberdaya alam yang memiliki fungsi penting dalam pembangunan suatu negara. Dalam pembangunan, hamper semua sektor memerlukan lahan seperti sector pertanian, industri, perdagangan, dan infrastruktur. Di sektor pertanian, lahan merupakan sumberdaya yang sangat penting, baik bagi petani maupun bagi pembangunan pertanian, hal ini didasarkan pada kenyataan bahwa di Indonesia sebagai negara agraris semua kegiatan pertanian masih bertumpu pada lahan karena lahan berperan penting

*) Prodi Ilmu Pemerintahan, Universitas Al Asyariah

Mandar, E-mail: rustam.irta17@gmail.com 
dalam kegiatan produksi yang dapat menghasilkan kebutuhan pangan yang dibutuhkan oleh setiap manusia.

Pembangunan nasional adalah pembangunan yang berorientasi pada manusia dengan tujuan untuk meningkatkan kesejahteraan dan taraf hidup masyarakat. upaya tersebut dapat dicapai dengan memenuhi kebutuhan dasar yang salah satunya yaitu kebutuhan tentang perumahan sebagaimana diamanatkan dalam pasal $28 \mathrm{H}$. Undang-Undang Dasar 1945, " setiap orang berhak hidup sejahtera lahir dan bathin, bertempat tinggal, dan mendapatkan lingkungan hidup yang baik dan sehat serta berhak memperoleh pelayanan kesehatan serta mendapatkan kesempatan persamaan dan keadilan.

Peningkatan jumlah penduduk yang semakin besar tentunya menuntut ketersediaan perumahan yang makin banyak, terutama banyak terjadi di kotakota besar. Namun jumlah lahan yang terbatas akan memicu harga lahan dan perumahan menjadi semakin mahal. Sebagai dampaknya, Kabupaten Polewali Mandar yang memiliki luas wilayah yang luas lokasi/ lahan pertanian paling dekat dengan kota kabupaten akan menjadi alternatif lokasi penyediaan perumahan, ketersediaan lahan dan harga lahan yang masih terjangkau dan masih murah menjadi keuntungan dalam mengembangkan kawasan perumahan di wilayah sekitar perkotaan. Keuntungan tersebut menjadi pendorong bagi pengembang perumahan (developer) untuk memperluas area pembangunannya sehingga memunculkan fenomena alih fungsi lahan pertanian menjadi kawasan pemukiman, namun yang kemudian menjadi satu masalah adalah bahwa alih fungsi lahan yang terjadi telah merambah pada area pertanian yang masih produktif.

Alih fungsi lahan pertanian sebenarnya bukan masalah baru. Sejalan dengan adanya peningkatan jumlah penduduk serta meningkatnya kebutuhan infrastruktur seperti, perumahan, jalan, perkantoran, dan bangunan lain menyebabkan kebutuhan akan lahan meningkat. Selain itu, pertumbuhan ekonomi yang tinggi menyebabkan pertumbuhan yang sangat cepat di beberapa sektor ekonomi. Pertumbuhan tersebut juga membutuhkan lahan yang lebih luas sehingga terjadi peningkatan kebutuhan lahan untuk pembangunan, sementara ketersediaan lahan relatif tetap menyebabkan persaingan dalam pemanfaatan lahan. Kebanyakan lahan yang dialihfungsikan umumnya adalah lahan-lahan pertanian karena land rent (sewa lahan).

Dalam hal ini, kebijakan yang berkaitan dengan tata ruang wilayah dan alih fungsi lahan merupakan kebutuhan yang sangat penting dalam upaya penataan serta pengaturan kecenderungan penggunaan lahan. Lebih dari itu diharapkan mampu mengendalikan laju alih fungsi lahan pertanian dalam 
suatu wilayah guna menjaga keseimbangan lingkungan. Kabupaten Polewali Mandar, menurut data Badan Pusat Statistik (BPS) tahun 2016 merupakan kabupaten yang memiliki kepadatan penduduk tertinggi di Provinsi Sulawesi Barat yaitu sebesar 422.793 Jiwa, dengan rincian Laki-Laki: 206.963 jiwa,Perempuan: 215.830 jiwa.

Peningkatan penduduk salah satunya akibat urbanisasi sebagai dampak dari perluasan kawasan kota Polewali Mandar. Hal tersebut juga berpengaruh terhadap peningkatan jumlah perumahan, di sisi lain masuknya para pengembang perumahan (developer) membuat kegiatan alih fungsi lahan di Polewali Mandar terus meningkat.

Dari luas lahan pertanian yang ada saat ini, sebagian telah dibebaskan untuk kawasan perumahan dan sudah mulai digarap oleh pihak pengembang. Bisnis perumahan di Polewali Mandar memang berkembang dengan pesat akhirakhir ini, bahkan sudah merambah ke beberapa Kecamatan di Kabupaten Polewali Mandar, seperti Kecamatan Polewali, Matakali, Benuang dan Kecamatan Wonomulyo, Untuk mengantisipasi tergusurnya area pertanian maka alih fungsi lahan telah diatur dalam Peraturan Daerah tentang Rencana Tata Ruang Wilayah (RTRW) Nomor 2 Tahun 2013, dengan harapan pihak pengembang (developer) dapat memperhatikan acuan Rencana Tata Ruang Wilayah (RTRW) tersebut dalam memilih lahan, Pemerintah Kabupaten Polewali Mandar telah membuat rancangan Peraturan Daerah yang merupakan bagian dari Perda RTRW, yaitu tentang Rancangan Penetapan Lahan Pertanian Pangan Berkelanjutan.

Dari uraian tersebut diatas, maka yang menjadi rumusan masalah pokok dalam penelitian ini adalah bagaimana Alih fungsi lahan pertanian menjadi kawasan Pemukiman/perumahan di Kecamatan Polewali Kabupaten Polewali Mandar

\section{METODE PENELITIAN}

a. Jenis Penelitian

Penelitian ini menggunakan jenis penelitian kualitatif dengan pendekatan deskriptif, yang menjadi fokus penelitian adalah:

1. Alih fungsi lahan pertanian menjadi kawasan Pemukiman/perumahan di Kecamatan Polewali Kabupaten Polewali Mandar.

a. Isi kebijakan dan kemanfaatan

b. Aktor pelaksana kebijakan

c. Koordinasi antar aktor pelaksana kebijakan

d. Prosedur alih fungsi lahan pertanian menjadi kawasan pemukiman 
2. Hasil kebijakan alih fungsi lahan pertanian menjadi kawasan Pemukiman perumahan di Kecamatan Polewali Kabupaten Polewali Mandar.
a. Pengunaan lahan pertanian menjadi kawasan
Pemukiman/perumahan
b. Pengendalian alih fungsi lahan pertanian menjadi kawasan
Pemukiman/perumahan.
c. Penataan kawasan perumahan.

\section{B. Pengumpulan Data}

Adapun teknik pengumpulan data yang akan digunakan dalam penelitian ini adalah :

1. Data Primer, adalah data yang diperoleh dari informan yang telah dipilih berdasarkan wilayah cakupan penelitian ini. Data primer diperoleh melalui:

1) Observasi yaitu mengamati secara langsung objek yang diteliti

2) Indef Interview atau wawancara secara mendalam mengenai penelitian yang dimaksud, dengan menggunakan pedoman wawancara.

2. Data Sekunder diperoleh melalui :

1) Studi pustaka, yaitu bersumber dari hasil bacaan literatur atau bukubuku atau data terkait dengan topik penelitian. Ditambah penelusuran data online, dengan pencarian data melalui fasilitas internet.

2) Dokumentasi, yaitu arsip, laporan tertulis atau daftar inventaris yang diperoleh terkait dengan penelitian yang dilakukan.

\section{Sumber Data}

Data yang dibutuhkan untuk penelitian ini berupa data sekunder yakni data dari pemerintah yaitu jajaran SKPD yang terdiri dari Balitbanren, Dinas Pertanian tanaman pangan, DPM-PTSP, Badan Pertanahan Nasional, Badan Lingkungan Hidup, dan Dinas PU Cipta Karya dan Tata Ruang, dan Pemerintah Kecamatan Polewali. Selain itu juga melibakan developer dan masyarakat. Setiap pihak yang terlibat tersebut memiliki peran masing-masing dalam prosedur perijinan alih fungsi yang kemudian dikomunikasikan bersama antar aktor dalam sebuah rapat bersama untuk menetukan kelayakan dari sebuah permohonan perijinan alih fungsi yang diajukan oleh developer. 


\section{Analisis Data}

Dalam menganalisis data yang diperoleh, peneliti akan menggunakan teknik analisis secara deskriptif kualitatif yakni data yang diperoleh akan dianalisis dan disajikan dalam bentuk kata-kata lisan maupun tertulis. Teknik ini bertujuan untuk menggambarkan secara sistematis fakta-fakta dan data data yang diperoleh. serta hasil-hasil penelitian baik dari hasil studi lapang maupun studi literatur untuk kemudian memperjelas gambaran hasil penelitian.

\section{HASIL PENELITIAN DAN PEMBAHASAN}

\section{Alih fungsi lahan pertanian menjadi kawasan perumahan.}

Alih fungsi lahan menurut Nasoetion dalam Nugroho (2004:153) diharapkan mampu mengakomodasi aktivitas pembangunan dan lokasi sesuai dengan peruntukannya dengan meminimalkan konflik kepentingan. Selanjutnya Koestoer (1997) berpendapat bahwa penggunaan lahan untuk pembangunan boleh dilakukan di suatu lokasi yang telah ditentukan oleh pemerintah daerah. Dalam Perda Nomor: 2 Tahun 2013 tentang Rencana Tata Ruang Wilayah penggunaan lahan pertanian untuk dialihfungsikan menjadi kawasan perumahan telah direncanakan dan diatur melalui penetapan untuk kawasan perumahan. Melalui penetapan tersebut kegiatan alih fungsi lahan pertanian boleh dilakukan bila lokasi tersebut sesuai dengan draf pemetaan RTRW Kabupaten Polewali Mandar.

\section{Hasil kebijakan alih fungsi lahan pertanian menjadi kawasan perumahan.}

1) Penggunaan lahan pertanian menjadi kawasan perumahan

Dari hasil penelitian yang telah dilakukan diketahui bahwa alih fungsi lahan pertanian baik dalam draft RTRW maupun praktiknya porsi terbesar digunakan untuk pengembangan kawasan perumahan. (lihat Tabel 1)

Dari jumlah ijin penggunaan tanah diketahui bahwa alih fungsi lahan mengalami peningkatan sebesar $19 \%$ di tahun 2017, dimana dilihat dari sisi pemanfaatan lahan paling besar digunakan untuk pembangunan kawasan perumahan yaitu sebesar $16 \%$. Proses alih fungsi tersebut tidak terjadi secara merata, dari 16 kecamatan hanya 7 (tujuh) kecamatan yang memiliki porsi besar dalam penggunaan lahan untuk pembangunan kawasan perumahan antara lain Kecamatan Campalagian, Wonomulyo, Mapilli, Tapango, Matakali, Polewali, dan Kecamatan Binuang. 
Tabel 1 Jumlah Ijin Perubahan Penggunaan Tanah Menurut Luas Tanah Tahun 2014 - 2017

\begin{tabular}{|c|c|c|c|c|c|}
\hline \multicolumn{2}{|c|}{ Luas Tanah (m2) } & \multicolumn{4}{|l|}{ Tahun } \\
\hline & & 2014 & 2015 & 2016 & 2017 \\
\hline \multirow[t]{2}{*}{ Jenis Tanah } & Sawah & 83.101ha. & 82.757 ha. & $65.540 \mathrm{ha}$ & $\begin{array}{l}259.60 \\
8 \text { ha } \\
\end{array}$ \\
\hline & Kering & - & - & - & - \\
\hline \multicolumn{2}{|l|}{ Total } & 83.101ha. & 82.757 ha. & 65.540 ha & $\begin{array}{l}259.60 \\
8 \mathrm{ha} \\
\end{array}$ \\
\hline Penggunaan & Perumahan & & & & 41.537 \\
\hline
\end{tabular}

\begin{tabular}{|l|l|l|l|l|l|}
\hline \multicolumn{2}{|l|}{ Luas Tanah (m2) } & \multicolumn{4}{l|}{ Tahun } \\
\hline \multicolumn{1}{|c|}{} & 2014 & 2015 & 2016 & 2017 \\
\hline \multirow{7}{*}{} & & & & & Ha \\
\cline { 2 - 6 } & Industri & - & - & - & - \\
\cline { 2 - 6 } & Lainnya & & & & \\
\cline { 2 - 6 } & Total & & & & \\
\hline
\end{tabular}

Sumber: Dinas Pertanian dan Pangan Kab.Polewali Mandar.

\section{Pengendalian alih fungsi lahan pertanian menjadi kawasan perumahan}

Nana Apriyana (2011) mengemukakan bahwa rencana tata ruang merupakan instrumen pengendali terhadap pemanfaatan ruang yang ada di daerah. Di Polewali Mandar, pengendalian alih fungsi lahan pertanian di atur melalui:

i) penetapan zonasi;

ii) perijinan;

iii) pemberian intensif dan disintensif; dan

iv) pengenaan sanksi.

Tindakan pengendalian khusus untuk mengontrol alih fungsi dari pemerintah daerah, baru menerbitkan Peraturan Daerah tentang Rencana Tata Ruang Wilayah, baik dalam bentuk program maupun kebijakan khusus dari pemerintah. Pengendalian hingga saat ini, juga masih berpedoman pada Perda Nomor 2 tahun 2013 tentang RTRW tahun 2012-2023 dan mekanisme perijinan. 


\section{3) Penataan kawasan perumahan}

Penataan kawasan perumahan adalah untuk menciptakan lingkungan hunian yang layak bagi masyarakat yang dilengkapi dengan sarana dan prasarana yang dibutuhkan. Di Kabupaten Polewali Mandar penataan tersebut telah diatur dalam Perda nomor 2 tahun 2013 tentang RTRW.

Dari hasil penelitian diketahui bahwa mayoritas pembangunan kawasan perumahan di Kabupaten Polewali Mandar, khususnya pada Kecamatan Polewali telah memenuhi kaidah penataan kawasan perumahan.

3. Faktor-Faktor penghambat dan pendukung implementasi kebijakan alih fungsi lahan pertanian menjadi kawasan perumahan di Kecamatan Polewali Kabupaten Polewali Mandar

Dalam proses implementasi suatu kebijakan tentunya akan ditemui beberapa faktor yang menjadi penghambat. Faktor penghambat yang ditemukan selama proses penelitian adalah bahwa Pemerintah Daerah dapat melakukan pengendalian dan penataan pada lahan yang melalui proses perijinan. Disisi lain, dalam rangka pengawasan di lapangan, Pemerintah terkendala oleh jumlah personil yang terbatas sehingga kinerja dari pengawasan menjadi kurang maksimal. Jika ke dua faktor ini dihubungkan dengan model implementasi kebijakan menurut Van Horn dan Van Meter dalam Subarsono (2012) maka faktor penghambat tersebut berada dalam disposisi implementor yang cenderung berpatokan pada proses perijinan dan kendala sumber daya manusia.

Di samping faktor penghambat, faktor pendukung juga ditemui dalam penelitian ini. Yang menjadi pendukung antara lain adalah adanya pertama rapat koordinasi antar aktor pelaksana kebijakan, dalam model kebijakan Van Horn dan Van Meter poin ini termasuk dalam hubungan antar organisasi yang berjalan dengan baik dalam menetukan kelayakan alih fungsi lahan pertanian menjadi kawasan perumahan. Kedua adalah peningkatan jumlah penduduk dan kemudahan aksesibilitas Kabupaten Polewali Mandar sehingga menjadi daya tarik untuk mengembangkan kawasan perumahan, poin ini termasuk dalam faktor sumberdaya non manusia yaitu bahwa lingkungan fisik dan sosial memiliki keuntungan bagi pengembangan kawasan perumahan. Jika poin ini dikaitkan dengan 7 kecamatan yang mengalami alih fungsi cukup besar, maka 
akan didapatkan hubungan yang saling terkait, yaitu bahwa lokasi Kecamatan tersebut merupakan lokasi yang strategis dengan memiliki akses cukup baik dilihat dari segi transportasi, perdagangan, jasan maupun industri.

\section{SIMPULAN}

Berdasarkan hasil penelitian dan pembahasan, maka dapat disimpulkan bahwa alih fungsi lahan pertanian baik dalam draft RTRW maupun praktiknya porsi terbesar digunakan untuk pengembangan kawasan perumahan, selain itu mayoritas pembangunan kawasan perumahan di Kabupaten Polewali Mandar, khususnya pada Kecamatan Polewali telah memenuhi kaidah penataan kawasan perumahan. Dalam proses implementasi suatu kebijakan tentunya akan ditemui beberapa faktor yang menjadi penghambat. Faktor penghambat yang ditemukan selama proses penelitian adalah bahwa Pemerintah Daerah dapat melakukan pengendalian dan penataan pada lahan yang melalui proses perijinan, selain itu Yang menjadi pendukung antara lain adalah adanya pertama rapat koordinasi antar aktor pelaksana kebijakan, dalam model kebijakan Van Horn dan Van Meter poin ini termasuk dalam hubungan antar organisasi yang berjalan dengan baik dalam menetukan kelayakan alih fungsi lahan pertanian menjadi kawasan perumahan. Kedua adalah peningkatan jumlah penduduk dan kemudahan aksesibilitas Kabupaten Polewali Mandar.

\section{DAFTAR PUSTAKA}

Anugrah F. 2005. Analisis Faktor-Faktor Yang Mempengaruhi Konversi

Lahan Sawah Ke Pengguna Non Pertanian Di Kabupaten Tanggerang.

Skripsi.

Institut Pertanian Bogor, Bogor.

BPS Kabupaten Polewali Mandar.(2015) Polewali Mandar Dalam Angka Tahun 2015. Polewali Mandar, BPS

BPS Kabupaten Polewali Mandar.(2016) Polewali Mandar Dalam Angka Tahun 2016. Polewali Mandar, BPS

Budihardjo, Eko.(1997) Arsitektur dan Kota di Indonesia. Bandung, Alumni. Jayadinata, Johara.T. (1999) Tata Guna Tanah Dalam Perencanaan Pedesaan, Perkotaan Dan Wilayah. Bandung,Penerbit ITB

Moleong, Lexy J. (2012) Metodologi Penelitian Kulitatif. Bandung: PT. Remaja Rosdakarya. 
Muchin, Imam Koeswahyono. (2008) Aspek Kebijaksanaan Hukum Penatagunaan Tanah Dan Penataan Ruang. Jakarta, Sinar Grafika.

Nugroho, Iwan dan Rochin Bahuri. (2004) Pembangunan Wilayah: Persepsi Ekonomi, Sosial dan Lingkungan. Jakarta, LP3ES.

Riant, Nugroho. (2012) Public Policy: Dinamika Kebijakan, Analisis Kebijakan,

Manajemen Kebijakan. Jakarta, Elex Media Komputindo.

Subarsono. (2012) Analisis Kebijakan Publik: Konsep Teori dan Aplikasi. Yogyakarta, Pustaka Pelajar.

Sujarto, Djoko. (2003) Pembangunan Kota Baru. Jakarta, Gunung Agung. Wahab, Solichin Abdul. (2012) Analisis Kebijakan: dari Formulasi ke Implementasi Kebijakan Negara. Jakarta, Bumi

Aksara Peraturan dan Perundang-Undangan:

Undang-Undang Nomor 1 Tahun 2011 Tentang Perumahan dan Kawasan Permukiman, perumahan adalah mencakup rumah, beserta dengan sarana, prasarana dan utilitas umum

Undang-Undang Nomor .26 Tahun 2007 tentang Penataan Ruang.

Peraturan Daerah No. 2 Tahun 2013 Tentang Tata Ruang Wilayah Kabupaten Polewali Mandar Tahun 2012-2032. , Pemerintah Daerah Kabupaten Polewali Mandar. 